\title{
Políticas da Formação Inicial de Professores, em Portugal, Decorrentes de Bolonha: posições da comunidade científica
}

\author{
Leal, Ana Rita ${ }^{1}$
}

Leite, Carlinda²

\section{Resumo}

O artigo analisa posições da comunidade científica acerca das políticas de formação inicial de professores do ensino básico, em Portugal, decorrentes do Processo de Bolonha. O corpus da análise foi constituído por artigos que focam a formação inicial de professores, publicados entre 2005 e 2015, em revistas de educação indexadas nas bases de dados Web of Science, Scopus e na Qualis A1, A2, B1, B2, B3, identificados a partir de palavras-chave. Essa análise, realizada pela técnica de análise de conteúdo, com apoio do Software Nvivo 11, permitiu constatar que as políticas de educação têm sido influenciadas por políticas internacionais que funcionam como uma agenda regulatória global. No que à formação de professores diz respeito, a comunidade científica, nos artigos publicados em revistas indexadas naquelas bases de dados, questiona as condições que estão a ser oferecidas para a socialização com a profissão e com as possibilidades de trazer a profissão para dentro da formação, ou seja, questiona as possibilidades que o Processo de Bolonha instituiu para a existência de uma formação adequada aos desafios que se colocam aos professores neste século $\mathrm{XXI}$.

Políticas de Formação de Professores. Processo de Bolonha. Formação Inicial de Professores. Ensino Básico.

\section{Abstracto}

El artículo analiza las posiciones de la academia sobre las políticas de formación inicial de los maestros de educación primaria en Portugal, resultantes del Proceso de Bolonia. El corpus de análisis consistió en artículos que se centran en la formación inicial del profesorado publicada entre 2005 y 2015 en revistas de educación indexadas en las bases de datos Web of Science, Scopus y Qualis A1, A2, B1, B2, B3, identificados a partir de palabras clave. Con el análisis, llevado a cabo mediante la técnica de análisis de contenido, con el apoyo de software Nvivo 11, se estableció que las políticas de educación han sido influenciadas por las políticas internacionales que actúan como una agenda regulatoria global. En lo que a la formación del profesorado se refiere, la comunidad científica, en los artículos publicados en revistas indexadas en aquellas bases de datos, cuestiona las condiciones que se ofrecen para la socialización con la profesión y para traer la profesión para dentro de la formación, es decir, cuestiona las

\footnotetext{
${ }_{1}^{1}$ Doutoranda da Faculdade de Psicologia e de Ciências da Educação, Universidade do Porto, Portugal. Pesquisadora do CIIE, Centro de Investigação e Intervenção Educativas ana.rita.pdce@gmail.com

${ }^{2}$ Professora Catedrática da Faculdade de Psicologia e de Ciências da Educação da Universidade do Porto, Portugal. Pesquisadora do CIIE, Centro de Investigação e Intervenção Educativas. carlinda@fpce.up.pt
} 
posibilidades que el Proceso de Bolonia proporciona para la existencia de una formación adecuada a los retos que se plantean al profesorado en este siglo XXI.

Políticas de Formación del Profesorado. Proceso de Bolonia. Formación Inicial del Profesorado. Enseñanza Primaria.

\section{Introdução}

Vivemos numa sociedade cada vez mais globalizada, com dinâmicas que têm modificado o modelo de desenvolvimento das sociedades e que afetam as políticas e as práticas educativas nacionais (DALE, 2001; ROBERTSON, 2009; Lima, 2011). No quadro destas políticas, no ensino superior, foram grandes as transformações decorrentes da assinatura da Declaração de Bolonha (Junho de 1999), e que teve como objetivo construir um Espaço Europeu de Ensino Superior (EEES) uniformizado, gerando o que alguns também chamaram de uma europeização das universidades e escolas superiores (LIMA; AZEVEDO; CATANI, 2008; MAASSEN; MUSSELIN, 2009). Esses dados são assinalados, por exemplo, por Dale (2001), quando refere que as políticas a nível local são versões resultantes de políticas a nível mundial. Este processo ocorre numa combinação de influências e interdependências transnacionais das múltiplas ligações entre o global, o distante e o local (BALL, 2001), o que complexifica o que tinha salientado Hargreaves (1998, p. 63) ao afirmar que vivemos um tempo de "pluralidade flutuante e constantemente instável de sistemas de crenças".

É nestes tempos de instabilidade que os desafios da pós-modernidade obrigam à criação de mecanismos estratégicos de adequação a novas realidades, exigindo que os professores desenvolvam competências holísticas, plurais e multifacetadas, capazes de apoiar a gestão de novas situações que os quotidianos vão apresentando. É também neste contexto que a formação de professores se tem transformado de modo a corresponder aos compromissos assumidos pelo Processo de Bolonha (PB) e aos desafios desta sociedade globalizada. A este nível, em Portugal tem-se assistido a uma rápida mudança na formação de professores (ADAMSON, 2012), seja pela organização dos cursos ou pela valorização da investigação e da reflexão nos currículos da formação inicial (ex.: BIERI; SCHULER, 2011; MASSON, 2011; STRUYVEN; DE MEYST, 2010). 
É tendo por base estas referências que este artigo dá conta de um estudo realizado na intenção de produzir conhecimento sobre posições que a comunidade científica, em Portugal, tem assumido face às políticas de formação inicial de professores do ensino básico decorrentes do Processo de Bolonha (PB).

\section{Contextualização política e teórica do estudo}

A formação inicial de professores foi, através dos diferentes momentos sociais, históricos e políticos, sofrendo uma evolução justificada na sua relação com as concepções de educação e com os papéis que lhe vão sendo atribuídos. Ao longo das últimas décadas essa evolução traduziu-se em mudanças na formação inicial dos professores, nomeadamente ao nível da estrutura curricular e dos planos de estudos, regulados por legislação que tem subjacente determinados modelos de formação. Instituída em Portugal em meados do século XX (NÓVOA, 1992), a formação inicial de professores tem convivido com dúvidas sobre a sua adequação a um perfil profissional capaz de corresponder às exigências que os discursos políticos e sociais lhe vão atribuindo. São exemplo disso os debates em torno das condições que a formação oferece de socialização com a profissão (GOMES, QUEIRÓS \& BATISTA, 2014; LEITE, 2014; LÜDKE \& BOING, 2004, NÓVOA, 2009; TARDIF \& LESSARD, 2009).

Relativamente a Portugal, como refere, em revisão, Leite (2012), até 1974, a profissionalização ocorria através de um estágio, por concurso, após formação académica nas áreas da docência (à exceção dos Professores do ensino primário e de Educação Física). ]

A partir dos finais dos anos 80 (séc. XX), as sucessivas alterações legislativas vieram tornar possível o enquadramento jurídico da Formação Inicial de Professores (FIP) nas reformas do sistema educativo português, algumas delas optando por um modelo de formação integrado, em substituição de uma formação bietápica (LEITE, 2005; FORMOSINHO, 2009), isto é, de uma formação para a prática da docência que só ocorre depois de uma formação académica que não a contempla. 
O enquadramento jurídico da FIP, a partir de 1986 (Lei de Bases do Sistema Educativo - LBSE), definiu, como exigência para uma qualificação profissional para o exercício da docência do Ensino Básico que essa formação passasse a ser realizada em instituições do Ensino Superior, reconhecidas pelo Ministério da Educação. Para a avaliação dos cursos de FIP, foi criado em 1998 o Instituto Nacional de Acreditação e da Formação de Professores (INAFOP), a quem foi atribuída a tarefa de definir um perfil de formação docente adequado a cada nível de ensino. Embora não fossem obrigatórios, estes perfis pretendiam constituir uma referência para a FIP. Com a mudança de governo em 2002, o INAFOP foi extinto (Lei nº 16-A/2002, de 31 de maio), criando-se um vazio na avaliação dos cursos que foi quebrado com a constituição, em 2007, da Agência de Avaliação e Acreditação do Ensino Superior (A3ES). Esta Agência, constituída na sequência do PB e da criação do Espaço Europeu de Ensino Superior (EEES), teve como objetivo garantir a qualidade dos cursos, agora reconhecidos no âmbito deste EEES.

De fato, o reconhecimento de diplomas obtidos nos distintos países implicou uma transformação relevante na organização dos cursos e na avaliação da sua qualidade (LEITE \& FERNANDES, 2014). Embora essa fosse uma preocupação desde o final do século XX (SANTOS, 2011), seja no seio das instituições, seja na discussão política e social, a avaliação da qualidade, em Portugal, passou a ter uma grande expressão a partir da criação da A3ES a quem foi atribuída a responsabilidade da "avaliação e a acreditação das instituições de ensino superior e dos seus ciclos de estudos, bem como o desempenho das funções inerentes à inserção de Portugal no sistema europeu de garantia da qualidade do ensino superior" (art. 3, n. ${ }^{\circ} 1$ do Decreto-Lei n. ${ }^{\circ}$ 369/2007 de 5 de novembro).

Quanto à FIP decorrente do PB, a partir de 2006 (Dec. Lei no 74/2006 de 24 de março) ela passou a estruturar-se segundo um modelo que decorre em duas etapas: uma primeira de formação geral a que se segue uma de preparação para a profissão, ou seja, numa lógica que, embora possa ser sequencial, tem na sua estrutura uma organização bietápica. É neste contexto que se situa o estudo que aqui se apresenta e que analisa posições da comunidade científica sobre o 
modelo de FIP decorrente dos compromissos de Bolonha e dos discursos de avaliação da qualidade.

\section{O Processo de Bolonha e as políticas dele decorrentes}

O Processo de Bolonha aparece, no contexto da Sociedade do Conhecimento e a criação do EEES como uma resposta para fomentar a qualidade, mobilidade e comparabilidade dos graus académicos e formações na Europa. Para tal, os países signatários acordaram adotar um sistema de diplomas claro, organizados em três ciclos de formação (1ํㅡㄹ Clo de graduação; $2^{\circ}$ Ciclo correspondente ao mestrado; $3^{\circ}$ Ciclo de doutoramento), e sujeitos a um sistema de avaliação da qualidade que os tornasse comparáveis a nível europeu (MAGALHÃES et al. 2013; PONTE, 2006; VEIGA \& AMARAL, 2011). Uma síntese da legislação produzida, decorrente do Processo de Bolonha, é sistematizado na tabela 1.

Tabela 1 Legislação publicada no âmbito do Ensino Superior 2005-2015

\begin{tabular}{|c|c|c|}
\hline Legislação & Âmbito & Instituição \\
\hline $\begin{array}{l}\text { Decreto-Lei } \\
\text { n.o } 42 / 2005 \\
\text { de } 22 \text { de } \\
\text { Fevereiro }\end{array}$ & $\begin{array}{l}\text { Princípios } \\
\text { reguladores } \\
\text { de } \\
\text { instrumentos } \\
\text { para a } \\
\text { criação do } \\
\text { EEES }\end{array}$ & $\begin{array}{l}\text { - estrutura de três ciclos no ensino superior } \\
\text { - graus académicos intercompreensíveis e comparáveis; } \\
\text { - organização curricular por unidades de crédito acumuláveis } \\
\text { e transferíveis } \\
\text { - instrumentos de mobilidade no espaço europeu de ensino } \\
\text { superior }\end{array}$ \\
\hline $\begin{array}{c}\text { Lei n.․․ } \\
\text { 49/2005, de } \\
30 \text { de Agosto }\end{array}$ & $\begin{array}{l}\text { Alteração da } \\
\text { Lei de Bases } \\
\text { do Sistema } \\
\text { Educativo }\end{array}$ & $\begin{array}{l}\text { - organização do ensino superior em três ciclos; } \\
\text { - sistema de ensino baseado na transmissão de } \\
\text { conhecimentos para o desenvolvimento de competências; } \\
\text { - sistema europeu de créditos curriculares (ECTS). }\end{array}$ \\
\hline $\begin{array}{l}\text { Decreto-Lei } \\
\text { n.. } 74 / 2006 \\
\text { de } 24 \text { de } \\
\text { março }\end{array}$ & $\begin{array}{l}\text { Graus e } \\
\text { diplomas do } \\
\text { Ensino } \\
\text { Superior }\end{array}$ & $\begin{array}{l}\text { - graus académicos e diplomas do ensino superior; } \\
\text { - princípios gerais do processo de acreditação dos cursos } \\
\text { - regras para a reorganização dos cursos em funcionamento; } \\
\text { - regras transitórias na criação de novos ciclos de estudos até } \\
\text { à entrada em funcionamento da A3ES }\end{array}$ \\
\hline$\frac{\frac{\text { Lei } n . \stackrel{\circ}{=}}{16 \text { de Agosto }}}{16 \text { de07 de }}$ & $\begin{array}{l}\text { Avaliação do } \\
\text { Ensino } \\
\text { Superior }\end{array}$ & $\begin{array}{l}\text { - regime de avaliação da qualidade no ensino superior } \\
\text { - cumprimento de parâmetros de desempenho } \\
\text { relacionados com a respetiva atuação e com os resultados } \\
\text { dela decorrentes, baseados em boas práticas internacionais }\end{array}$ \\
\hline
\end{tabular}




\begin{tabular}{|c|c|c|}
\hline $\begin{array}{c}\text { Lei } \mathrm{n}^{\circ} \\
\text { 62/2007, de } \\
10 \mathrm{de} \\
\text { Setembro }\end{array}$ & $\begin{array}{l}\text { Regime } \\
\text { jurídico das } \\
\text { instituições } \\
\text { de ensino } \\
\text { superior }\end{array}$ & $\begin{array}{l}\text { - constituição, atribuições e organização, o funcionamento e } \\
\text { competência dos seus órgãos das instituições de ensino } \\
\text { superior, tutela e fiscalização }\end{array}$ \\
\hline $\begin{array}{c}\text { Decreto-Lei } \\
\text { n. } 369 / 2007 \text {, } \\
\text { de } 5 \text { de } \\
\text { Novembro }\end{array}$ & $\begin{array}{l}\text { Agência de } \\
\text { Avaliação e } \\
\text { Acreditação } \\
\text { do Ensino } \\
\text { Superior }\end{array}$ & $\begin{array}{l}\text { - criação a Agência de Avaliação e Acreditação do Ensino } \\
\text { Superior e aprova os seus estatutos } \\
\text { - definição do sistema de avaliação da qualidade } \\
\text { - apresentação de normas de procedimento sobre a avaliação } \\
\text { e acreditação dos cursos }\end{array}$ \\
\hline $\begin{array}{c}\text { Decreto-Lei } \\
\text { n.o } 107 / 2008, \\
\text { de } 25 \text { de } \\
\text { Junho }\end{array}$ & $\begin{array}{l}\text { Princípios } \\
\text { reguladores } \\
\text { de } \\
\text { instrumentos } \\
\text { para a } \\
\text { criação do } \\
\text { EEES }\end{array}$ & $\begin{array}{l}\text { - elaboração, por cada instituição, de um relatório anual, } \\
\text { público, acerca do progresso da concretização do PB; } \\
\text { - aperfeiçoamentos no regime transitório de avaliação externa } \\
\text { de novos ciclos de estudos até ao início de atividade da A3ES; } \\
\text { - maior flexibilidade no acesso à formação superior; } \\
\text { - apoio aos licenciados e mestres que, após a obtenção do } \\
\text { grau, se encontrem a realizar estágio profissional; } \\
\text { - simplificação do processo de comprovação da titularidade } \\
\text { dos graus. }\end{array}$ \\
\hline $\begin{array}{c}\text { Decreto-Lei } \\
\text { n.o } 115 / 2013 \text {, } \\
\text { de } 7 \text { de } \\
\text { Agosto }\end{array}$ & $\begin{array}{l}\text { Graus e } \\
\text { diplomas do } \\
\text { Ensino } \\
\text { Superior }\end{array}$ & $\begin{array}{l}\text { - clarificação dos requisitos relativos à composição do corpo } \\
\text { docente das instituições de ensino superior universitárias e } \\
\text { politécnicas para cada um dos ciclos de estudos conferentes } \\
\text { de grau académico } \\
\text { - os ciclos de estudos só podem ser ministrados nos locais } \\
\text { para onde foram acreditados e registados } \\
\text { - atualizações do regime jurídico dos graus e diplomas do } \\
\text { ensino superior }\end{array}$ \\
\hline
\end{tabular}

No que à formação de professores diz respeito, ela decorreu numa tensão entre a necessidade de se ajustar aos compromissos decorrentes do PB e os desafios que advêm de um exercício da docência adequado à diversidade dos contextos educacionais (NÓVOA, 2002).

A própria legislação produzida nesta última década dá conta dessa tensão, como é sistematizado na tabela 2. Por um lado, considera-se ser necessária uma sólida formação no aprofundamento de conhecimentos relacionados com os conteúdos das áreas da docência e, por outro, deverem os professores possuir competências profissionais capazes de promoverem a aprendizagem e 0 sucesso escolar dos diversos alunos que passaram a frequentar a instituição escolar (LEITE, 2005). 
Tabela 2 Legislação publicada no âmbito da Formação Inicial de professores 2005-2015

\begin{tabular}{|c|c|c|}
\hline Legislação & Âmbito & Institui \\
\hline $\begin{array}{l}\text { Decreto - Lei } \\
\text { n. } .^{4} / 2007 \\
\text { de } 22 \text { de } \\
\text { fevereiro }\end{array}$ & $\begin{array}{c}\text { Habilitação } \\
\text { profissional para a } \\
\text { docência desde a } \\
\text { educação pré- } \\
\text { escolar ao ensino } \\
\text { secundário }\end{array}$ & $\begin{array}{l}\text { - substituiu os modelos de formação então em vigor } \\
\text { por um modelo sequencial, organizado em dois } \\
\text { ciclos de estudos } \\
\text { - primeiro ciclo de formação de base na área da } \\
\text { docência; } \\
\text { - segundo ciclo visa reforçar e aprofundar os } \\
\text { conhecimentos necessários à docência nas áreas } \\
\text { de conteúdo e nas disciplinas abrangidas pelo grupo } \\
\text { de recrutamento para que visa preparar }\end{array}$ \\
\hline$\frac{\frac{\text { Decreto-Lei }}{\mathrm{n} .{ }^{\circ} 79 / 2014}}{\text { de } 14 \text { de maio }}$ & $\begin{array}{l}\text { Formação de } \\
\text { Professores }\end{array}$ & $\begin{array}{l}\text { - aumento da duração dos ciclos de estudos e do } \\
\text { peso relativo nas áreas da docência } \\
\text { - definição da correspondência entre as formações } \\
\text { e os grupos de recrutamento }\end{array}$ \\
\hline
\end{tabular}

No quadro deste desafio de apelo à qualidade e de uma formação de professores capaz de a concretizar, esperou-se que a FIP proporcionasse experiências profissionais enriquecedoras e não apenas situações de acumulação de conhecimentos destinados a processos de transmissão de informação (LEITE, 2005). Como se depreende, isso implicaria um modelo de formação que rompa com uma orientação tradicional, que atribuía às instituições educativas apenas o papel de reproduzir o conhecimento existente, na lógica de uma "cultura considerada única" (LEITE, 2003, p. 2). Para isso, seria necessário que a FIP os preparasse para irem além das rotinas e do cumprimento da burocracia (CACHAPUZ, 2009) tornando-os capazes de novos projetos educativos e de práticas pedagógicas promotoras de uma renovação da educação (NÓVOA, 2002).

Face à complexidade das situações que ocorrem no dia-a-dia profissional dos professores, espera-se deles o recurso a metodologias diversificadas, centradas na aprendizagem individual e coletiva, que permita o desenvolvimento de competências pessoais e sociais. Por isso, torna-se necessário que na formação de professores seja reforçado o contacto com a profissão de modo a que sejam desenvolvidas competências profissionais que permitam lidar com as mudanças e os desafios inerentes a cada situação. Espera-se, pois, uma 
formação que não se limite aos conteúdos técnicos ou científicos das disciplinas que os professores lecionam (LEITE \& FERNANDES, 2013).

É no quadro desta concepção de educação e formação de professores que os cursos de FIP passam a ser avaliados por agências, orientadas por agendas globais internacionais (DALE, 2000; PACHECO, 2011; LEITE, 2014; LEITE \& FERNANDES, 2014) e por modelos que se enquadram no que é definido pelo Quadro Europeu de Qualificações. No caso da FIP ela passou a situar-se no nível 7 por corresponder a um mestrado. Apesar desta maior qualificação académica, e como atrás foi referido, a componente relativa à prática profissional para a docência ocorre apenas no 2.ำ ciclo (mestrado), podendo ter a duração de 1 ano (para educadores de infância) ou de 1,5 anos (para professores das primeiras séries do ensino básico) ou de 2 anos, para professores dos restantes níveis de escolaridade básica.

\section{Procedimento Metodológico}

Como já foi referido, este artigo tem como objetivo dar conta de posições da comunidade científica portuguesa face ao modelo de FIP decorrente do PB, identificando os sentidos que lhe são atribuídos. Para tal, recorreu-se à análise de artigos, em língua portuguesa, publicados nos últimos 10 anos (2005-2015) em revistas de circulação internacional. Para a identificação desses artigos, foram consultadas as bases de indexação mais reconhecidas na área da Educação e que correspondem respectivamente à: Thomson Reuters' Journal Citation Reports (que contém o ranking das revistas com factor de impacto [IF] indexadas na Web of Science); SCImago Journal Rank (ranking das revistas indexadas na Scopus); Qualis classificações A1, A2, B1, B2 e B3 (ranking de revistas elaborado pelo sistema brasileiro).

Depois desta consulta, foram identificadas as revistas de língua portuguesa pertencentes a cada uma das referidas bases de dados. Essa identificação exigiu uma análise exaustiva de todas as revistas pertencentes a cada base de dados, que permitiu eliminar repetições de revistas (que aparecem em mais do que uma base de dados). Esse processo levou à identificação de 218 revistas em língua portuguesa, distribuídas da forma que a tabela 3 enuncia. 
Tabela 3 Revistas de língua portuguesa nas diferentes bases de dados

\begin{tabular}{lc}
\multicolumn{1}{c}{ Base de dados } & Revistas de Língua Portuguesa \\
Web of Science Core Collection & 3 \\
\hline Scopus & 21 \\
Qualis A1 e Qualis A2 & 73 \\
Qualis B1, B2, B3 & 121 \\
Total & 218 \\
\hline
\end{tabular}

Depois de identificadas as revistas, a procura dos artigos, embora adaptada a cada base de dados, foi feita para o período temporal entre 2005 e 2015 e recorrendo às seguintes palavras-chave: "Políticas de Formação de Professores", "Processo de Bolonha", " Formação Inicial de Professores", "Ensino Básico".-Este procedimento permitiu identificar 115 artigos distribuídos pelas bases de dados, como é expresso na Tabela 4.

Tabela 4 Artigos encontrados nas diferentes bases de dados

\begin{tabular}{lc}
\hline \multicolumn{1}{c}{ Base de dados } & Artigos \\
Web of Science Core Collection & 1 \\
Scopus & 43 \\
Qualis A1 e Qualis A2 & 48 \\
Qualis B1, B2, B3 & 23 \\
Total & 115
\end{tabular}

Destes 115 artigos foi lido o resumo de modo a selecionar aqueles que estavam, efetivamente, relacionados com a temática do estudo, ou seja, a FIP decorrente do PB. Essa leitura eliminou 105 artigos, ou seja, dos 115 iniciais, apenas 10 se relacionavam com a temática do estudo. A tabela 5 representa a distribuição desses 10 artigos por cada uma das bases de dados. 
Tabela 5 Distribuição dos artigos relacionados com a temática em estudo, por cada uma das bases de dados

\begin{tabular}{lc}
\hline Base de dados & Artigos encontrados \\
Web of Science Core Collection & 0 \\
\hline Scopus & 2 \\
Qualis A1 e Qualis A2 & 2 \\
Qualis B1, B2, B3 & 6 \\
Total & 10
\end{tabular}

Foram esses 10 artigos que constituíram o corpus de análise para o presente trabalho. Uma vez que a pesquisa se prende com o foco de cada artigo, e não propriamente com o autor, optou-se por codificar esses artigos atribuindo-lhes números de 1 a 10. A identificação dos 10 artigos está feita na secção das referências bibliográficas. Cada um dos artigos foi sujeito a uma análise de conteúdo (BARDIN, 1994; ESTEVES, 2006), com recurso ao software informático Nvivo 11.

O material recolhido foi codificado a partir de dois tipos de categorias: as categorias pré-definidas, construídas no início do trabalho e que pretendiam identificar a existência ou não de adesão ao modelo de FIP resultante do PB, e as categorias emergentes, ou seja, as que foram emergindo no decorrer da análise.

Para além disso, a análise permitiu ainda identificar subcategorias que não estavam previstas à partida. Foi a partir desta matriz e da quantificação de referências que a interpretação das tendências foi construída.

\section{Apresentação de discussão dos resultados}

A análise dos artigos publicados entre 2005 e 2015 em revistas de língua portuguesa indexadas nas bases de dados selecionadas e atrás referidas, sobre formação inicial de professores, decorrente do Processo de Bolonha, permitiu a sua categorização em torno das seguintes posições: (1) Adesão incondicional, (2) Adesão com condicionantes, (3) Rejeição.

A cada uma destas posições foram associadas as subcategorias que a análise dos artigos permitiu identificar e que se relacionam com: sentidos das 
políticas; qualidade da FIP; perceções de formadores; possibilidades de implementação da FIP; dificuldades da implementação da FIP.

A figura 1 traduz a relação entre as categorias e as subcategorias identificadas. Refira-se ainda que a análise levou a considerar uma quarta categoria, que designámos por "Outras", e que inclui como subcategorias: "questões em foco" que orienta o artigo; data de publicação do artigo; base de dados em que o artigo está indexado.

Figura 1: Categorias e subcategorias

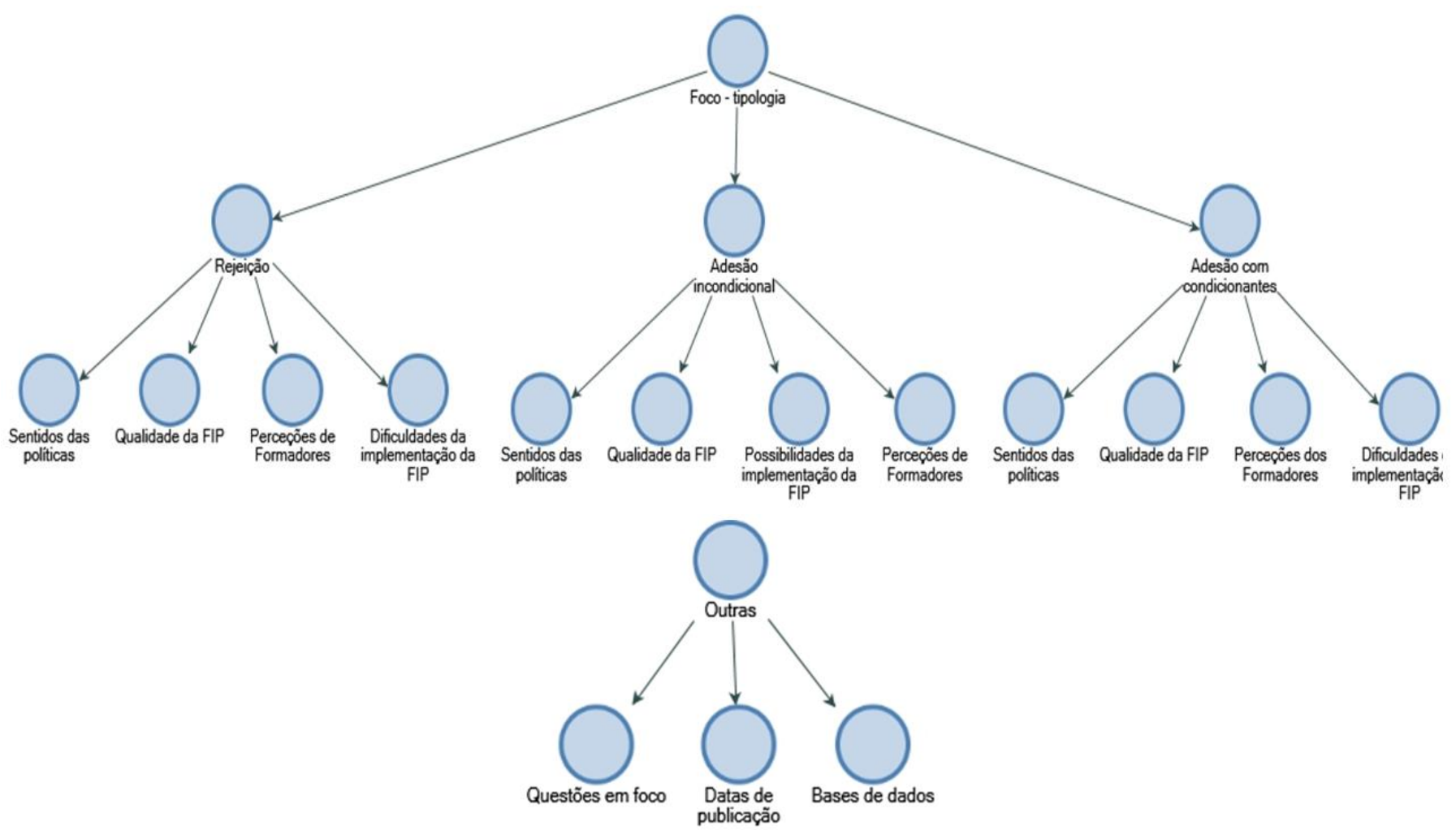

Apoiámo-nos nas subcategorias da categoria "Outras" para identificarmos os artigos e os situarmos nas questões que têm por foco, datas em que foram publicados e respetivas bases de indexação. A tabela 6 dá disso conta. 
Tabela 6 Caraterísticas dos 10 artigos analisados: ano, indexação e questões focadas

\begin{tabular}{|c|c|}
\hline $\begin{array}{l}\text { Indexação } \\
\text { de Revistas }\end{array}$ & Artigo Publicado em 2006 \\
\hline Qualis A1 & $\begin{array}{l}\text { Artigo 4: referencial de competências profissionais a desenvolver na } \\
\text { FIP do 1ํㅡㄹ }\end{array}$ \\
\hline \multicolumn{2}{|r|}{ Artigos Publicados em 2012} \\
\hline \multirow[t]{3}{*}{ Qualis B3 } & Artigo 5: modelo de FIP do decorrente do PB \\
\hline & $\begin{array}{l}\text { Artigo 7: perspetivas dos órgãos de direção e gestão de uma IES, } \\
\text { professores e estudantes, sobre o modelo de FIP }\end{array}$ \\
\hline & $\begin{array}{l}\text { Artigo 10: legislação que regulam o quadro de formação e currículos de } \\
\text { formação estabelecidos pelas IES - politécnicas e universitárias }\end{array}$ \\
\hline \multicolumn{2}{|r|}{ Artigos Publicados em 2013} \\
\hline \multirow[t]{2}{*}{ Scopsus } & $\begin{array}{l}\text { Artigo 1: políticas de currículos para FIP e questões curriculares } \\
\text { emergentes }\end{array}$ \\
\hline & Artigo 2: formação científica dos licenciados PB na Matemática \\
\hline Qualis B2 & Artigo 8: FIP em Portugal, especificidades e incertezas \\
\hline \multicolumn{2}{|r|}{ Artigo Publicado em 2014} \\
\hline Qualis B1 & Artigo 6: modelo de FIP resultante da adequação, em Portugal, ao PB \\
\hline \multicolumn{2}{|r|}{ Artigos Publicados em 2015} \\
\hline Qualis A1 & $\begin{array}{l}\text { Artigo 3: discursos dos formadores da FIP do } 1^{\circ} \text { CEB da UTAD em } \\
\text { relação às práticas de avaliação das aprendizagens }\end{array}$ \\
\hline Qualis B1 & Artigo 9: perceções sobre as políticas de ES e de FIP \\
\hline
\end{tabular}

Os resultados decorrentes da análise dos 10 artigos são apresentados em função das categorias atrás referidas e do número de referências codificadas para cada uma delas. A tabela 7 dá conta da distribuição dessas referências distribuídas por cada uma das categorias: adesão incondicional; adesão com condicionantes; rejeição. 
Tabela 7 Distribuição das Referências Codificadas nas dimensões: Adesão incondicional, Adesão com condicionantes, Rejeição

\begin{tabular}{cccc}
\hline ARTIGOS & $\begin{array}{c}\text { ADESÃO } \\
\text { INCONDICIONAL }\end{array}$ & $\begin{array}{c}\text { ADESÃO } \\
\text { COM CONDICIONANTES }\end{array}$ & REJEIÇÃo \\
\hline 1 & 0 & 4 & 26 \\
\hline 2 & 0 & 10 & 0 \\
\hline 3 & 21 & 0 & 0 \\
\hline 4 & 0 & 19 & 0 \\
\hline 5 & 3 & 5 & 12 \\
\hline 6 & 0 & 0 & 13 \\
\hline 7 & 0 & 9 & 0 \\
\hline 8 & 0 & 4 & 10 \\
\hline 9 & 0 & 46 & 0 \\
\hline 10 & 14 & 0 & $\mathbf{6 1}$ \\
\hline Total & $\mathbf{3 8}$ & $\mathbf{9 7}$ & \\
\hline
\end{tabular}

Como se constata pela leitura da tabela 7 , as posições dos autores dos 10 artigos identificados apontam claramente num sentido de adesão com condicionantes ou rejeição, embora ocorram muitas situações cujo foco predominante é o de adesão incondicional rejeitando, no entanto, as mudanças levadas a cabo na Formação Inicial de Professores decorrentes do Processo de Bolonha. A sustentar a posição da academia que defende uma adesão incondicional às políticas decorrentes do $\mathrm{PB}$, apesar de esta ser a categoria com menos referências codificadas, encontramos argumentos como:

Uma vez que são as instituições de Ensino Superior que criam, privilegiadamente, as condições de "fabricação cognitiva de saberes relacionados com contextos específicos da economia" (PACHECO, 2011, p. 19), é a elas que cabe o papel de promover a aprendizagem daqueles conhecimentos e das referidas competências, com a participação ativa dos estudantes na construção dessas aprendizagens. Daí que essa aquisição de conhecimentos e de competências tem que ser feita por meio da aprendizagem e do trabalho autônomos dos estudantes, tal como previsto pela Declaração de Bolonha (1999). (Artigo 3).

Como razões que justificam a adesão à política instituída por Bolonha, estão, entre outras, o facto de apontar para uma formação mais flexível, que permite a transição de cursos e de 
opções de formação, e que valoriza a ação e o envolvimento dos estudantes na construção das suas próprias aprendizagens, isto é, uma adesão ao paradigma de formação assente na aprendizagem e de rutura com a lógica tradicional de ensino. (Artigo 5).

Se, por um lado, a realidade profissional com que os futuros professores se irão deparar lhes obriga a fazer aprendizagens de conhecimentos e de competências diversificados que lhes permitam dar respostas adequadas às exigências dessa realidade, por outro lado, o processo de Bolonha conduz a que essas aprendizagens sejam feitas pelos estudantes de forma autônoma, embora supervisionada e orientada pelos seus professores. (Artigo 3).

Perante a tarefa basilar de formar com qualidade os professores do 1. CEB e não podendo deixar de cumprir determinações tutelares, as instituições de ensino superior portuguesas que a assumem devem, ao abrigo da autonomia decisional de que auferem, construir os seus próprios planos de estudos para a licenciatura e para o mestrado, bem como estabelecer os requisitos de ingresso nos dois ciclos. (Artigo 10).

Pelo contrário, e de forma a refutar estas ideias de apoio às políticas de FIP, decorrentes de Bolonha, são bastantes os argumentos de rejeição apresentados nos artigos analisados. Alguns exemplos são:

Um dos aspectos que merece reflexão como retrocesso para a formação de professores na declaração de Bolonha tem relação com a organização da formação em dois momentos, em que a formação específica pode vir a desenrolar-se em duas etapas, sendo a formação específica para a docência apenas obtida na segunda, isto é, no $2^{\circ}$ ciclo (correspondente ao que virá a ser o nível de mestrado) (Leite, 2006, p. 287). Essa lógica aponta para um retrocesso no que se refere a uma organização de formação "bi-etápica" as consequências desse modelo poderão contribuir para um processo de desvalorização da formação do professor, fato que tem sido atribuído aos mestrados portugueses. Isso leva a um enfraquecimento da prática da investigação, que tem sido marca da educação escolar, do campo curricular e da docência. (Artigo1).

Contrariamente ao modelo que tinha vindo a ser instituído por algumas instituições de formação, e que procurava organizar-se na lógica da socialização gradual com a profissão, o modelo decorrente de Bolonha retrocedeu ao que Cunha (2003, p. 68) critica quando se refere a uma concepção que exige "que o aprendiz primeiro domine a teoria para depois entender a prática e a realidade. (Artigo1).

De facto, no caso da formação inicial de professores, e contrariamente ao que até então acontecia, ela não se inicia 
desde a entrada no curso de ensino superior, ou seja, há uma formação de $1^{\circ}$ ciclo (licenciatura), em que os estudantes têm uma formação geral e/ou fundada em conhecimentos disciplinares, a que se segue um $2^{\circ}$ ciclo (mestrado), em que ocorre a formação para o exercício da docência. Essa estrutura da formação de professores, embora corresponda a uma formação de mais alto valor académico - trata-se de um mestrado - não tem uma duração muito mais longa do que a formação que estava em vigor antes da adequação ao Processo de Bolonha (em alguns casos pode ter mais um ano) e impede a organização de um currículo de formação em que se vá progressivamente ampliando o contato com as situações profissionais docentes. (...) É neste sentido que continua a justificar-se interrogar as possibilidades que esse modelo tem de conseguir melhorar a qualidade da formação de professores, tal como tem sido veiculado pelas directrizes europeias. (Artigo 5).

Apesar disso, sendo limitado o tempo disponível para os estudantes, futuros educadores e professores, contactarem com situações de exercício profissional, ficam limitadas as possibilidades deste modelo de formação de professores concretizar o que tem sido apontado por Nóvoa $(1992,2009)$ quando refere que a formação se constrói dentro da profissão e onde a experiência ocupa lugar de destaque. (Artigo 5).

A análise do modelo de formação instituído revela uma estrutura curricular que se afasta de um modelo integrado, separando a formação teórica da formação relativa à prática docente, e que oferece um tempo curto de socialização com a profissão. Ou seja, revela poucas possibilidades de uma formação que se organize no quadro das ideias sustentadas pelos discursos académicos e que seja capaz de concretizar uma qualidade social das aprendizagens, das instituições e da profissão não fechada em critérios economicistas e de pendor neoliberal. (Artigo 6).

(...) uma formação que condiciona o contato com situações e o tempo de acesso a saberes de ordem pedagógica e didática a uma duração tão curta - e que em Portugal vai de 1 ano a 2 anos - tem de ter evidentes efeitos na socialização com a profissão e na existência de condições para o estabelecimento de relações entre a teoria e a prática. (Artigo 6).

(...) o modelo de formação de professores instituído pela adequação ao Processo de Bolonha optou por uma estrutura que reduz o tempo de socialização com a profissão (TARDIF; LESSARD, 2009; LOPES, 2009; LEITE, 2012) e tem contribuído para quebrar a relação entre a teoria e a prática (...).(Artigo 6).

Em síntese, face aos discursos políticos que têm circulado nestes últimos anos em Portugal, e que anunciam a procura da qualidade, a análise do modelo de formação de professores do ensino básico que está a ser seguido revela uma ampla margem de diferença entre a bondade para que apontam esses discursos e os processos que os concretizam. (Artigo 6). 
Todavia, com a divisão da formação inicial em dois ciclos distintos acabou-se por acentuar um processo formativo não integrado, em que cada ciclo autonomamente passou a reger seus objetivos e conteúdos formativos. Assim, se tem uma formação inicial sequencial e bi-etápica, em que primeiro se oferta uma formação generalista, de formação de base, para depois, na etapa subsequente, uma formação especializada, mais profissionalizante, que, no entender de Morgado (2007), constituiu um retrocesso em alguns aspectos da formação inicial de professores que já estavam consagrados, tais como: interdisciplinaridade, articulação entre conhecimentos científicos e didático-pedagógicos, entre outros. (Artigo 8).

A posição da academia que mais referências apresenta, e como mostra a tabela 7, é sem dúvida a categoria "adesão com condicionantes", onde os autores apresentam diferentes razões pelas quais o Processo de Bolonha é uma resposta interessante para responder aos novos desígnios e exigências da formação de professores do século XXI, apesar de deixar algumas dúvidas e inquietações quanto à sua implementação bem sucedida. Os excertos que se seguem são alguns dos argumentos veiculados pelos artigos analisados:

(...) o Processo de Bolonha (PB) e o Regime Jurídico de Habilitação Profissional para a Docência (RJHPD) - D.L. noํ 43/2007 - poderiam constituir uma oportunidade para introduzir as necessárias mudanças na FP suscetíveis de virem a traduzirse na melhoria da sua qualidade, apesar de se reconhecer que a mudança não decorre apenas da legislação, mas também, e muito, da ação dos seus agentes (...). (Artigo 9).

Se tivermos em atenção que os resultados da investigação prévia remetem para falhas na organização e no funcionamento da FP relacionadas com a preparação científica dos professores recém-formados (relativamente ao conhecimento científico do conteúdo) e para problemas de ordem didática (Estrela et al., 2002), consideramos que esses resultados devem ser alvo de particular atenção, no sentido de se reequacionarem modos de ação na condução dos processos de FP. (Artigo 9).

(...) muito embora o grau de adesão às políticas de FP decorrentes do PB se situe num pólo positivo, principalmente no que a princípios orientadores diz respeito, há um conjunto de reservas que são expressas pelos participantes e que surgiram do confronto com a prática de formação, ou seja, relativamente à dimensão de operacionalização.(Artigo 9).

Isso remete, por um lado, para uma reflexão sobre os modos de organização e concretização da formação que têm vindo a ser desenvolvidos, tendo em vista uma eventual otimização dos processos e resultados. Por outro lado, e como anteriormente foi defendido (SOUSA-PEREIRA, 2012), remete para uma reflexão 
sobre as políticas de FP no sentido de equacionar eventuais redefinições (...). (Artigo 9).

(...) o D. L. no 43/2007 reforçou a componente de Formação nas Áreas de Docência ao nível do $1^{\circ}$ Ciclo de Estudos (licenciatura em Educação Básica) e concedeu maior destaque à Prática de Ensino Supervisionada e às Didáticas Específicas no $2^{\circ}$ Ciclo de Estudos (cursos de mestrado), será de tentar tirar partido dessa situação para melhorar a preparação dos estudantes a esse nível. Será que, apesar de organizada estruturalmente em duas etapas distintas, não será de se pensar a FP num continuum, preparando esse profissional para o desempenho docente ao longo dos dois Ciclos de Estudos que conferem habilitação profissional para a docência? (Artigo 9).

Tendo em consideração que a legislação tem sido alterada, no sentido de uma maior adaptação dos cursos aos princípios de Bolonha, importa-nos também analisar se houve uma alteração da posição da academia fruto dessa evolução legislativa. Assim e na intenção de poder fazer interpretações complementares, foi ainda estabelecida uma relação com a data de publicação do artigo, no sentido de verificar a existência de alguma relação entre essa data e a da publicação de legislação sobre formação de professores.

Uma análise das posições académicas encontradas nos artigos publicados, em função dos anos dessas publicações, permite inferir alguns aspetos interessantes para o debate. Para essa tarefa, sistematizámos na tabela 8 a distribuição das referências codificadas nas posições Rejeição, Adesão incondicional, Adesão com condicionantes, em função dos anos dessas publicações.

Tabela 8 - Distribuição das Referências Codificadas nas dimensões Adesão incondicional, Adesão com condicionantes, Rejeição de acordo com o ano de publicação do artigo

\begin{tabular}{cccc}
\hline $\begin{array}{c}\text { Anos de } \\
\text { publicação }\end{array}$ & $\begin{array}{c}\text { Adesão } \\
\text { incondicional }\end{array}$ & $\begin{array}{c}\text { Adesão com } \\
\text { condicionantes }\end{array}$ & Rejeição \\
\hline 2006 & 0 & 21 & 0 \\
2012 & 3 & 22 & 22 \\
2013 & 28 & 22 & 43 \\
2014 & 0 & 0 & 15 \\
2015 & 26 & 76 & 0 \\
\hline
\end{tabular}

As primeiras publicações analisadas neste estudo (2005) correspondem a uma fase importante da adaptação da legislação do ensino superior, que 
correspondeu à criação do EEES (Decreto-Lei n.ำ42/2005) e consequente ajuste na Lei de Bases do Sistema Educativo e no Decreto-Lei que regula os graus e

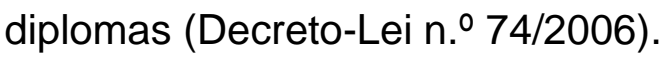

Talvez por isso se justifique que os artigos publicados nessa época apontem para uma adesão aos Princípios de Bolonha apesar dos condicionantes que ele pode trazer. Ainda não estavam implementados os processos que alteraram a FIP e, por isso, os académicos ainda não se posicionavam numa adesão incondicional ou numa rejeição.

Refira-se ainda que, embora não seja possível encontrar uma linearidade ou uma tendência muito definida ao longo do tempo, percebe-se a existência de um hiato de investigação entre 2007 e 2012. Muito provavelmente será justificado pelos esforços de adaptação, nas instituições de ensino superior, a critérios de organização dos cursos decorrentes da criação da A3ES (Decreto-Lei n.․․ 369/2007) e dos processos para a avaliação, nomeadamente os da necessidade de serem instituídos mecanismos internos de qualidade.

Após esse período de revisão das ofertas formativas e discussão das suas implicações, percebe-se a existência em 2013 e 2014 de um novo impulso de publicações nestas revistas marcadas por um sentido de rejeição ou aceitação com condicionantes. Certamente que os contributos e a revisão da legislação sobre os graus e diplomas (Decreto-Lei n. -115/2013) e a legislação específica sobre a formação de professores (Decreto-Lei n. $79 / 2014)$, respondendo às questões sobre a duração dos ciclos de estudos e dúvidas sobre o peso relativo nas áreas da docência podem estar associadas a uma mudança de tendência nas publicações para uma adesão com condicionantes ou uma adesão incondicional. Apesar da distância temporal entre a legislação produzida e o seu reflexo na publicação específica nesta área, parece verificar-se uma tendência no sentido da valorização da duração e do peso das áreas da docência na formação de professores.

Se centrarmos, agora, a nossa atenção nas bases de dados de indexação das revistas onde os artigos analisados foram publicados, encontramos um dado bastante interessante. Na tabela 9 podemos ver a distribuição das referências codificadas de acordo com essas bases de dados. 
Não deixa de ser interessante constatar que encontramos o mesmo número de referências nas revistas Qualis B3 e B1, bem como nas revistas indexadas na SCOPUS, sendo que não foram encontrados artigos em língua portuguesa publicados em revistas indexadas na Web of Science.

A FIP decorrente do PB embora seja uma temática recente e que está na ordem do dia, não está ainda muito presente nas publicações destas revistas em língua portuguesa, situação que merece a nossa atenção e que exige uma pesquisa futura que permita compreender a razão dessa não presença.

Tabela 9 Distribuição dos artigos pelas bases de dados

\begin{tabular}{c|l|l|l|l|l|l}
\hline \multicolumn{1}{c|}{ Artigos } & \multicolumn{1}{c}{ Scopus } & \multicolumn{1}{l}{ Qualis A1 } & Qualis A2 & Qualis B1 & Qualis B2 & Qualis B3 \\
\hline 1 & & & & & & \\
\hline 2 & & & & & & \\
\hline 3 & & & & & & \\
\hline 4 & & & & & & \\
\hline 5 & & & & & & \\
\hline 6 & & & & & & \\
\hline 7 & & & & & & \\
\hline 8 & & & & & & \\
\hline 9 & & & & & & \\
\hline 10 & & & & & & \\
\hline
\end{tabular}

\section{Conclusão}

Retomando o objetivo do estudo a que se reporta este artigo, lembra-se que a nossa intenção foi dar conta de posições da comunidade científica relativamente às alterações nas políticas de formação inicial de professores que decorreram do Processo de Bolonha em Portugal. Para isso, foram identificados artigos em língua portuguesa publicados entre 2005 e 2015 em revistas de circulação internacional que focassem a FIP. Este procedimento metodológico, ao selecionar revistas indexadas em bases de dados reconhecidas pela academia (Web of Science, SCOPUS e Qualis), tornou evidente que a temática, embora atual, não constitui uma das prioridades destas revistas. O número de artigos é diminuto, o que pode estar também relacionado com a pressão que é colocada aos investigadores para publicarem em revistas de língua inglesa. 
A comunidade científica, independentemente das posições que defendem em relação ao $\mathrm{PB}$, é unânime em reconhecer que vivemos numa sociedade globalizada, num movimento que influencia a implementação de políticas e práticas educativas comuns (DALE, 2001; ROBERTSON, 2009; LIMA, 2011). Também ao nível do ensino superior percebemos esses movimentos, atualmente impulsionados pela criação do EEES e pelos compromissos assumidos pelo PB. A sua concretização trouxe consigo grandes alterações que fizeram-se sentir, também, ao nível da formação de professores (ADAMSON, 2012), quer pela organização dos cursos, quer pelo valor que passou a ser atribuído à investigação nos currículos da formação inicial (BIERI \& SCHULER, 2011).

Face a um discurso internacional de apelo a que o ensino superior se pautasse por critérios que permitissem a comparabilidade dos graus académicos no EEES e a sua qualidade, o PB surgiu como uma resposta para fomentar essa qualidade e mobilidade. Por isso, os cursos passariam também a estar sujeitos a um sistema de avaliação da qualidade que os tornasse comparáveis a nível europeu (MAGALHÃES et al. 2013; VEIGA \& AMARAL, 2011; PONTE, 2006).

Perante este cenário, diversas vozes no seio da comunidade científica se manifestaram, apresentando discursos e posições diferentes. Neste trabalho demos conta disso mesmo focando a nossa atenção na formação inicial de professores. De fato, a análise de artigos publicados sobre esta temática permitiu saber que, embora exista um grupo, menor, que apresenta uma posição de adesão incondicional às políticas decorrentes do PB, essas posições têm por base a ideia que o PB veio dar legitimidade às Instituições de Ensino Superior para que fossem criadas as condições ideais para os estudantes desenvolverem a autonomia e competências pessoais e sociais. Outro motivo que os autores dos artigos analisados apresentam para veicularem uma posição de adesão incondicional ao PB é o facto deste permitir uma formação mais flexível, capaz de se ajustar a uma maior diversidade de opções por parte dos estudantes, ao mesmo tempo que os envolve na aprendizagem de forma ativa e autônoma (LEITE \& FERNANDES, 2014). 
No entanto, a par de posições de adesão, há também que assinalar a existência de um conjunto de referências no sentido da rejeição destas políticas, e que foram mesmo consideradas como um movimento de retrocesso na qualidade da formação (MORGADO, 2007). Esta posição de rejeição tem na sua origem, quer o fato do PB ter tido como efeito que a FIP passasse a ocorrer em dois momentos, em vez de um modelo integrado de formação, que pelo fato de ter recorrido a um processo que diminui o período de socialização com a profissão (LEITE \& FERNANDES, 2014).

A maior parte dos argumentos usados pelos autores que defendem a rejeição de políticas decorrentes de PB reforçam o facto deste novo modelo de FIP reduzir o tempo de socialização com a profissão, imprimindo a necessidade de redirecionar o modelo de formação de professores em vigor de modo a "trazer a profissão para dentro da formação" (Nóvoa, 2009). Para isso, é necessário que na formação de professores seja reforçado o contacto com a profissão de modo a que sejam desenvolvidas competências profissionais que permitam lidar com as mudanças e os desafios inerentes a cada situação. Espera-se, pois, uma formação que não se limite aos conteúdos técnicos ou científicos das disciplinas que os professores lecionam (LEITE \&; FERNANDES, 2013).

Como na apresentação e discussão dos resultados foi dado conta, a posição que recolheu mais referências codificadas foi a da "adesão com condicionantes". Nesta posição, vários autores apontam as oportunidades criadas pelo Processo de Bolonha para responder aos novos desígnios e exigências da formação de professores do século XXI, não deixando, contudo, de suscitar algumas dúvidas e inquietações quanto à sua implementação bemsucedida (LEITE, 2005). Tendo em consideração as exigências da profissão e a necessidade de promoção de práticas de socialização adequadas (LEITE, 2014; LÜDKE \& BOING, 2004), percebem-se as críticas apontadas à legislação que enquadra estas políticas e que foi neste artigo apresentada. Com a alteração da legislação, para colmatar falhas na organização e no funcionamento dos cursos, percebe-se que, progressivamente, passou a haver uma tendência para maior aceitação e crença nas possibilidades deste Processo. 
A possibilidade de reconhecimento de diplomas e a organização dos cursos para o desenvolvimento de competências, que vão para além do mero acumular de conhecimentos e execução de rotinas (CACHAPUZ, 2014; LEITE, 2005), podem constituir contributos relevantes para melhorar a qualidade na FIP de modo a preparar professores que positivamente respondam às características dos diversos alunos que frequentam a instituição escolar (LEITE, 2005; LEITE \& FERNANDES, 2014; NÓVOA, 2002). É no quadro desta concepção de educação e formação de professores que os cursos de FIP passaram a ser avaliados por agências orientadas por agendas globais internacionais (DALE, 2000; PACHECO, 2011; LEITE, 2014; LEITE \& FERNANDES, 2014) e por modelos que se enquadram no que é definido pelo Quadro Europeu de Qualificações.

Em síntese, sendo este um tópico recente, importa continuar os estudos e a reflexão centrada na melhoria da qualidade da formação inicial de professores. Os seus contributos terão certamente impacto na melhoria da formação dos docentes e, certamente também, na reflexão sobre o sistema educativo e a formação das próximas gerações.

\section{Referências}

ADAMSON, Bob. International comparative studies in teaching and teacher education. Teaching and Teacher Education, 28 (5), p. 641-648, 2012. Disponível: <http://media.journals.elsevier.com/content/files/s0742051×12000340-04221112.pdf>. Acesso em: 11, Maio, 2013.

BALL, Stephen. Diretrizes e políticas globais e relações políticas locais em educação. Currículo sem Fronteiras, 1(2), p. 99-116., 2011 Disponível em: $<$ http://www.curriculosemfronteiras.org/vol1iss2articles/ball.pdf2001>. Acesso em: 26 Mar 2013.

BARDIN, Laurence. Análise de Conteúdo. Lisboa, Edições 70, 281 p., 1994.

BIERI, Christine; SCHULER, Patricia. Cross-curricular competencies of student teachers: a selection model based on assessment centre admission tests and study success after the first year of teacher training. Assessment \& Evaluation in Higher Education, 36 (4), 399-415, 2011. Disponível em: $<$ http://lib.education.vnu.edu.vn:8121/bitstream/123456789/5067/1/TeacherEducation1 1501.pdf>. Acesso em: 05, setembro, 2015.

CACHAPUZ, António. A Construção do Espaço Europeu de Ensino Superior. Um case study da globalização. REP - Revista Espaço Pedagógico, 16 (2), p. 123-134, 2009. Disponível em: <http://seer.upf.br/index.php/rep/article/view/2220/1435>. Acesso em: 12 Novembro, 2015.

DALE, Roger Globalization: a new world for comparative education? In J. Schriewer (ed.), Discourse Formation in Comparative Education. Berlin: Peter Lang, p. 87-109, 2000. 
DALE, Roger. Globalização e educação: demonstrando a existência de uma 'cultura educacional mundial comum' ou localizando uma 'agenda globalmente estruturada para a educação'?. Educação, Sociedade \& Culturas, 16, p. 133-169, 2001.

ESTEVES, Manuela. Análise de conteúdo. In: LIMA, J. A.; PACHECO, J. A. (Orgs.), Fazer investigação. Contributos para a elaboração de dissertações e teses. Porto: Porto Editora, p. 105-126., 2006.

FORMOSINHO, João (coord.). Formação de professores, aprendizagem profissional e ação docente. Porto: Porto Editora, 2009.

GOMES, P., QUEIRÓS, P., \& BATISTA, P. A socialização antecipatória para a profissão docente: estudo com estudantes de Educação Física. Sociologia, 28, 167 - 192., 2014.

HARGREAVES, Andrew. Os professores em tempos de mudança. 0 Trabalho e a Cultura dos Professores na Idade Pós-Moderna. Lisboa: Mc Graw-Hill. (1998).

LEITE, Carlinda. A formação de professores em Portugal e a Declaração de Bolonha. Comunicação proferida na Reitoria da Universidade de Aveiro, em 18-072003.

LEITE, Carlinda. Percursos e tendências recentes da formação de professores em Portugal. Educação, 57 (3), p. 371-389, 2005. Disponível em: < https://repositorioaberto.up.pt/bitstream/10216/41366/2/86621.pdf>. Acesso em 5 de Outubro de 2012.

LEITE, Carlinda. Qualidade da educação superior e formação de professores: Uma análise a partir da situação em Portugal. In C. Broilo \& M. Cunha (Eds.), Qualidade da educação superior: Grupos investigativos internacionais em diálogo (pp. 99-117). Araraquara (São Paulo): Junqueira \& Marin Editores, 2012.

LEITE, Carlinda; FERNANDES, Preciosa. A formação inicial de professores em Portugal - para uma reflexão sobre o modelo decorrente do Processo de Bolonha. In A. Lopes (org.), Formação inicial de professores e de enfermeiros: identidades e ambientes (p. 55-67). Lisboa: Mais Leituras, 2013.

LEITE, Carlinda. Políticas de formação de professores do ensino básico em Portugal uma análise focada no exercício da profissão. Revista Educação e Cultura

Contemporânea, vol. 11, № 26, p. 8-29, 2014.

LEITE, Carlinda; FERNANDES, Preciosa. Avaliação, qualidade e equidade. Avaliação: Revista da Avaliação da Educação Superior (Campinas), 19(2), 421438. 2014.

Lima, Licínio. Políticas educacionais, organização escolar e trabalho dos professores. Educação: Teoria e Prática, 21 (37), p.1 - 19, 2011.

Lima, L. C.; Azevedo M.L.; Catani, A. M. O processo de Bolonha, a avaliação da educação superior e algumas considerações sobre a Universidade Nova. Avaliação: Revista da Avaliação da Educação Superior, 13 (1), 7-36, 2008.

LÜDKE, Menga; BOING, Luiz Alberto. Caminhos da profissão e da profissionalidade docentes. Educação \& Sociedade, vol. 25, núm. 89, Centro de Estudos Educação e Sociedade Campinas, Brasil, 2004. Disponível em:

$<$ http://www.redalyc.org/articulo.oa? $i d=87314213005$ >. Acesso em: 3 de Setembro, 2015.

MAASSEN, Peter; MUSSELIN, Chrisitine. European Integration and the Europeanisation of Higher Education. In Amaral, Neave; Musselin and Maassen 2009. Disponível em 
<http://www.academia.edu/15264978/European_Integration_and_the_Europeanisation _of_Higher_Education>. Recuperado em 3 setembro 2016.

MASSON, Gisele. As relações entre a agenda pós-moderna e os fundamentos das políticas de formação de professores no Brasil. Arquivos Analíticos de Políticas Educativas, 19 (19), 2011. Disponível em http://epaa.asu.edu/ojs/article/view/764. Acesso em 14/03/2013.

MAGALHÃES, António. et al. Creating a common grammar for European higher education governance. Journal Higher Education Quarterly, Vol. 65, no.1, p 95-112, 2013. Disponível em

https://sigarra.up.pt/fpceup/pt/pub geral.pub view?pi pub base id=87510\&pi pub r1 $\mathrm{id}=$ Acesso em 10 de Dezembro 2015.

MORGADO, José Carlos. Formação e desenvolvimento profissional docente: perspectivas europeias. Braga : Centro de Investigação em Educação da Universidade do Minho, 2007. Disponível em:

<http://repositorium.sdum.uminho.pt/handle/1822/8151>. Acesso em 5 janeiro de 2012

NÓVOA, António. Formação de professores e profissão docente. In A. Nóvoa (Org.)

Os Professores e sua Formação. Lisboa: Publicações Dom Quixote, 1992.

Nóvoa, António. Formação de professores e trabalho pedagógico. Lisboa: Educa, 2002

Nóvoa, António. Para uma formação de professores construída dentro da profissão. In A. Nóvoa (org.),Professores: imagens do futuro presente, p. 25-46, Lisboa: Educa, 2009.

PACHECO, José Alberto Pacheco. Currículo, Aprendizagem e Avaliação. Uma abordagem face à agenda globalizada. Revista Lusófona de Educação, 17, 75-90, 2011.

PONTE, José Pedro da. Implementação do Processo de Bolonha a nível nacional - Formação de Professores, 2006. Disponível em:

$<$ http://www.fcsh.unl.pt/english/Docs/Bolonha Formacao Professores.pdf. $>$ Acesso em 4 de Fevereiro de 2013

ROBERTSON, Susan. O Processo de Bolonha da Europa torna-se global: modelo, mercado, mobilidade, força intelectual ou estratégia para construção do Estado?", Revista Brasileira de Educação, vol. 14, n. 42; Rio de Janeiro: ANDEP, 2009.

Struyven, Katrien, \& De Meyst, Marijke. Competence-Based Teacher Education: Illusion or Reality? An Assessment of the Implementation Status in Flanders from Teachers'and Studentes' Points of View. Teaching and teacher education, 26: 14951510, 2010.

SANTOS, Sérgio Machado. Análise comparativa dos processos europeus para a avaliação e certificação de sistemas internos de garantia da qualidade. Lisboa: A3ES, 2011.

Tardif, M., \& Lessard, C. O trabalho docente - elementos para uma teoria da docência como profissão de interações humanas (5를 Ed). Petrópolis: Vozes, 2009.

Veiga, Amélia; Amaral, Alberto. "Uma interpretação do olhar da História sobre Bolonha", História - Revista da FLUP, IV série: 1, pp 30-40, 2011. Disponível em: $<$ http://docplayer.com.br/21815463-Historia-revista-da-flup-iv-serie-volume-12011.html> Acesso em 25 de março de 2013.

Legislação consultada: 
Decreto-Lei n. $92 / 2005$, de 22 de Fevereiro - Princípios reguladores de instrumentos para a criação do Espaço Europeu Ensino Superior

Lei n. 9 49/2005, de 30 de Agosto - Alteração da Lei de Bases do Sistema Educativo Decreto-Lei n. $.74 / 2006$, de 24 de março - Graus e diplomas do Ensino Superior Lei n. ${ }^{\circ}$ 38/2007, de 16 de Agosto - Avaliação do Ensino Superior

Decreto -Lei n. ${ }^{\circ}$ 43/2007, de 22 de fevereiro - Habilitação profissional para a docência desde a educação pré-escolar ao ensino secundário

Lei n. 62/2007, de 10 de Setembro - Regime jurídico das instituições de ensino superior

Decreto-Lei n.ำ 369/2007, de 5 de Novembro - Agência de Avaliação e Acreditação do Ensino Superior

Decreto-Lei n. 107/2008, de 25 de Junho - Princípios reguladores de instrumentos para a criação do EEES

Decreto-Lei n. $-115 / 2013$, de 7 de agosto - Graus e diplomas do Ensino Superior Decreto-Lei $n . .79 / 2014$, de 14 de maio- Formação de Professores

\section{Artigos aos quais se refere o estudo}

Artigo 2 Fernandes, Susana; Conceição, Ana. Pré-cálculo e a formação inicial de professores de Matemática: resultados preocupantes de um teste diagnóstico. Revista Lusófona de Educação, v. 25, 135 -155, 2013. Disponível em < <Go to ISI>://SCIELO:S1645-72502013000300009>, Acesso em 01/ 2016.

Artigo 4 Leitão, Álvaro. Para uma nova cultura profissional: uma abordagem da complexidade na formação inicial de professores do $1^{\circ}$ CEB. Revista Portuguesa de Educação, v. 19, n.2, p.51-84, 2006. Disponível em <Go to ISI>://SCIELO:S0871-91872006000200004>, Acesso em 01/ 2016.

Artigo 5 Leite, Carlinda. A formação inicial de professores no quadro dos compromissos de Bolonha: contributos para uma reflexão sobre o que foi instituído em Portugal. Form. Doc., Belo Horizonte, v. 04, n. 07, p. 10-18, jul./dez. 2012. Disponível em http://formacaodocente.autenticaeditora.com.br, Acesso em 01/2016.

Artigo 6 Leite, Carlinda. Políticas de formação de professores do ensino básico em Portugal: uma análise focada no exercício da profissão. Revista Educação e Cultura Contemporânea, v. 11, n.26, p. 8 - 29, 2014. Disponível em: <http://www.rcaap.pt/detail.jsp?id=oai:repositorioaberto.up.pt:10216/77376>, Acesso 01/ 2016.

Artigo 7 Mouraz, Ana; Leite, Carlinda; Fernandes, Preciosa. A formação inicial de professores em Portugal decorrente do Processo de Bolonha: uma análise a partir do "olhar" de professores e de estudantes. Revista Portuguesa de Pedagogia, 2012, Vol. 46, Issue. 2, p. 189-209, 2012. Disponível em: < https://digitalis.uc.pt/handle/10316.2/28261 > Acesso 01/ 2016

Artigo 8 Nunes, Celly; Nunes Herika. A formação inicial de professores em Portugal: hoje em dia, todo professor deve ser....Educação em Perspectiva, Viçosa., v. 4, n. 1, p. 224-237, 2013. Disponível em: 
http://www.seer.ufv.br/seer/educacaoemperspectiva/index.php/ppgeufv/artic le/view/416, Acesso 01/2016

Artigo 9 Sousa-Pereira, Fátima; Leite, Carlinda; Carvalho, José. Políticas de formação inicial de professores em Portugal no Processo de Bolonha: uma análise intrainstitucional a partir de práticas de formação. Educação Unisinos, v. 19(1):6-21, janeiro/abril 2015. Disponível em: https://repositorio-aberto.up.pt/bitstream/10216/78788/2/114897.pdf, Acesso em 01/2016. 